\title{
Un enterramiento colectivo en cueva del III milenio AC en el centro de la Península Ibérica: el Rebollosillo (Torrelaguna, Madrid)*
}

\author{
A mid-third millennium BC collective burial cave in central Iberia: El Rebollosillo \\ (Torrelaguna, Madrid)
}

\begin{abstract}
Pedro Díaz-del-Río ${ }^{\mathrm{a}}$, Susana Consuegra ${ }^{\mathrm{a}}$, Julia Audije ${ }^{\mathrm{b}}$, Susana Zapata ${ }^{\mathrm{b}}$, Óscar Cambra ${ }^{\mathrm{b}}$,

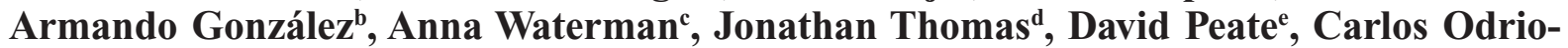
zola $^{\text {f, Rodrigo Villalobos }}$, Primitiva Bueno ${ }^{\mathrm{h}}$ y Robert H. Tykot $^{\mathrm{i}}$
\end{abstract}

\section{RESUMEN}

El Rebollosillo es una pequeña cueva kárstica situada en el centro de la Península Ibérica utilizada para la disposición de enterramientos secundarios en la mitad del III milenio AC. Presentamos resultados bioantropológicos, isotópicos $\left({ }^{87} \mathrm{Sr} /{ }^{86} \mathrm{Sr}, \delta^{13} \mathrm{C}\right.$ y $\left.\delta^{18} \mathrm{O}\right)$ y 16 dataciones radiocarbónicas de los restos humanos, una descripción cuantificada de los 43 fragmentos cerámicos y de caracterización mineralógica de 6 cuentas recuperadas durante la excavación de 1989, cuatro de las cuales probablemente proceden de Palazuelo de las
Cuevas (Zamora). El análisis bioantropológico indica un mínimo de 21 individuos con todos los rangos de edad y sexo. Se han detectado bajos porcentajes de patologías, mayoritariamente cálculo dental y caries, con casos puntuales de cribra orbitalia, periostosis y artrosis. La disposición de los restos sugiere que sólo los adultos recibieron un tratamiento claramente individualizado, quizás acorde con un estatus adquirido con la edad. Proponemos que el registro representa la última fase de un programa mortuorio cuyas etapas previas debieron desarrollarse en otros lugares y valoramos estos resultados en el contexto del registro funerario regional.

\footnotetext{
* Investigación desarrollada en el contexto de los proyectos HAR2013-47776-R y CGL2012-35199 del Ministerio de Ciencia y Competitividad y el proyecto Cód. 099100 de la FUAM.

a Instituto de Historia, CSIC. C/ Albasanz 26-28. 28037 Madrid. Correos e.: pedro.diazdelrio@cchs.csic.es http://orcid.org/00000002-4150-6185; susana.consuegra@cchs.csic.es http://orcid.org/0000-0002-5032-6856.

b Laboratorio de Poblaciones del Pasado (LAPP), Dpto. de Biología, Facultad de Ciencias. Universidad Autónoma de Madrid. C/ Darwin 2. Ciudad Universitaria de Cantoblanco. 28049 Madrid. Correos e.: julia.audije@titulado.uam.es http://orcid.org/0000-00019990-1965, susana.zapata@titulado.uam.es http:// orcid.org/0000-0001-6528-1171; oscar.cambra@uam.es http://orcid.org/0000-00017730-3294; armando.gonzalez@uam.es http://orcid.org/0000-0001-9216-1220.

c Mount Mercy University, Dept. of Natural and Applied Sciences. 150 Basile Hall. Cedar Rapids. Iowa 52402 USA. Correo e.: awaterman@mtmercy.edu http://orcid.org/0000-0002-5321-2539.

d Dept. of Anthropology, University of Iowa. 114 Macbride Hall. Iowa City. Iowa 52242 USA. Correo e.: jonathan-t-thomas@ uiowa.edu http://orcid.org/0000-0002-4989-0089.

e Dept. of Earth \& Environmental Sciences, University of Iowa, 121 Trowbridge Hall, Iowa City, IA 52242, USA. Correo e.: david-peate@uiowa.edu http:// orcid.org/0000-0002-7813-5824.

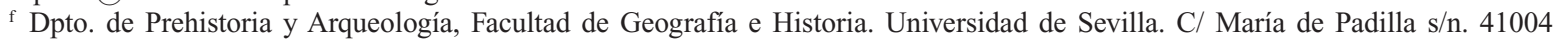
Sevilla. Correo e.: codriozola@us.es http:// orcid.org/0000-0002-4411-2528.

g Dpto. de Prehistoria, Arqueología, Antropología Social y Ciencias y Técnicas Historiográficas. Universidad de Valladolid. Plaza del Campus s/n. 47004 Valladolid. Correo e.: rodrigovillalobosgarcia@gmail.com http://orcid.org/0000-0002-9064-1295.

h Área de Prehistoria. Universidad de Alcalá de Henares. C/ Colegios 2. 28801 Alcalá de Henares. Madrid. Correo e.: p.bueno@ uah.es http://orcid.org/0000-0001-8958-8928.

i Dept. of Anthropology. University of Florida. 4202 East Fowler Ave, SOC107, Tampa, FL 33620-7200. Correo e.: rtykot@usf. edu http://orcid.org/0000-0002-8154-9331.

Recibido 1-VII-2016; aceptado 6-II-2017.
}

Copyright: (C) 2017 CSIC. Este es un artículo de acceso abierto distribuido bajo los términos de una licencia de uso y distribución Creative Commons Attribution (CC-by) España 3.0. 


\begin{abstract}
El Rebollosillo is a small karstic cave located in the center of Iberia used for the disposition of secondary burials during the mid third millennium $B C$. We present bioanthropological, isotopic $\left({ }^{87} \mathrm{Sr} /{ }^{86} \mathrm{Sr}, \quad \delta^{13} \mathrm{C}\right.$ y $\left.\delta^{18} \mathrm{O}\right)$ analyses and 16 radiocarbon dates on human remains, as well as mineralogical characterization of 6 beads (4 of them variscite from Palazuelo de las Cuevas, Zamora), and a quantitative analysis of 43 pottery fragments recovered during the 1989 excavations. A minimum of 21 individu-als have been identified, covering all age ranges and sex. Low percentages of pathologies have been detected, mainly dental calculus and caries, with specific cases of cribra orbitalia, periostosis and arthritis. Only adults received a clearly individualized treatment, suggestive of achieved status. We interpret the evidence as a multi-staged mortuary program, the last phase of which is documented at the site, with previous stages perhaps carried out elsewhere, and we evaluate these results in the context of the regional funerary record.
\end{abstract}

Palabras clave: Enterramiento colectivo; Enterramiento secundario; Estatus adquirido; Edad del Cobre; Península Ibérica; Bioantropología; Análisis isotópico; Radiocarbono; Variscita.

Key words: Collective burial; Multi-staged mortuary program; Achieved status; Copper Age; Iberia; Bioanthropology; Isotopic analyses, Radiocarbon; Variscite.

\section{EL YACIMIENTO}

El Rebollosillo (Torrelaguna, Madrid) (ETRS89, Huso 30, x 451593, y 4517452, z 809 $\mathrm{m})$ es una pequeña cueva natural de aproximadamente $23 \mathrm{~m}^{2}$ situada en las rocas carbonáticas cretácicas del macizo kárstico que se dispone al sur del Sistema Central. Formada durante el Plioceno, es una de las múltiples cuevas de la zona que fueron utilizadas durante la Prehistoria reciente como lugares de enterramiento, abrigo o vivienda estacional ${ }^{1}$.

El lugar está topográficamente retirado aunque a unos $5 \mathrm{~km}$ de la fértil vega del río Jarama, una de las principales cuencas fluviales de la región.

\footnotetext{
${ }^{1}$ Como son la Cantera de los Esqueletos (Tortuero), el Abrigo de los Enebrales (Tamajón) y La Cueva (Bañuelos) en Guadalajara, o la cueva de la Ventana, del Aire, de las Avispas (Patones) o de la Higuera (Torremocha del Jarama) en Madrid. Una rigurosa y actualizada revisión del registro funerario de la Prehistoria reciente en la región de Madrid en Aliaga (2014).
}

Se dispone en una vaguada secundaria por la que fluye un arroyo estacional. La boca se abría sobre una banda caliza que discurre paralela a escasamente $2 \mathrm{~m}$ de la base del arroyo de Santa Lucía, regato que confluye en el de San Vicente, afluente del Jarama. La anchura de la boca en su zona más estrecha llega a los $1,72 \mathrm{~m}$, abriéndose en su interior hasta un máximo de $4,13 \mathrm{~m}$. El eje longitudinal medía 4,85 $\mathrm{m}$ antes de la intervención arqueológica. La grieta presenta una inclinación hacia el interior del $11,2 \%$, con un desnivel de $84 \mathrm{~cm}$ entre boca y fondo (Fig. 1).

El yacimiento se descubrió tras la recuperación en el verano de 1989 de un pequeño conjunto de restos humanos y un cuenco de carena baja fabricado a mano ${ }^{2}$. Previa excavación, la superficie de la cueva presentaba abundantes rocas calizas, sedimentos removidos y ocasionales fragmentos óseos. La extensión inicial de la cueva era de $15,15 \mathrm{~m}^{2}$. En toda la zona occidental la roca caliza afloraba en una banda de $5,9 \mathrm{~m}^{2}$, dejando exclusivamente $9,25 \mathrm{~m}^{2}$ con depósito arqueológico. El fondo, colmatado de techo a base, sugería que la cueva era en realidad la boca de un karst holofósil.

\section{LA EXCAVACIÓN}

Tras la limpieza de la superficie se planteó la 'cata 1' (1 x 1,50 m) sobre el lugar del que, por las huellas, supusimos fueron extraídos los materiales que permitieron el descubrimiento arqueológico. Su excavación permitió recuperar un conjunto fragmentado y disperso de restos óseos humanos con una mayor densidad en el ángulo sureste. La cata contaba con un máximo de 15 $\mathrm{cm}$ de potencia estratigráfica hasta el sedimento arcilloso que consideramos estéril, por lo que se

\footnotetext{
2 Depositados junto con el preceptivo aviso en la Dirección General de Patrimonio Histórico de la Comunidad de Madrid que financió un sondeo de valoración de dos meses. En la campaña participó un pequeño grupo de arqueólogos voluntarios bajo la dirección de uno de nosotros (PDR) y la codirección de Eduardo Penedo Cobo. La escasa potencia del yacimiento y su frecuentación como refugio ocasional de excursionistas nos llevó a solicitar ampliar la excavación hasta agotar en lo posible la zona potencialmente afectada. Esta decisión fue providencial: en nuestra última visita (2014) el reciente abancalado de la ladera hacia irreconocible la boca de la cueva.
} 

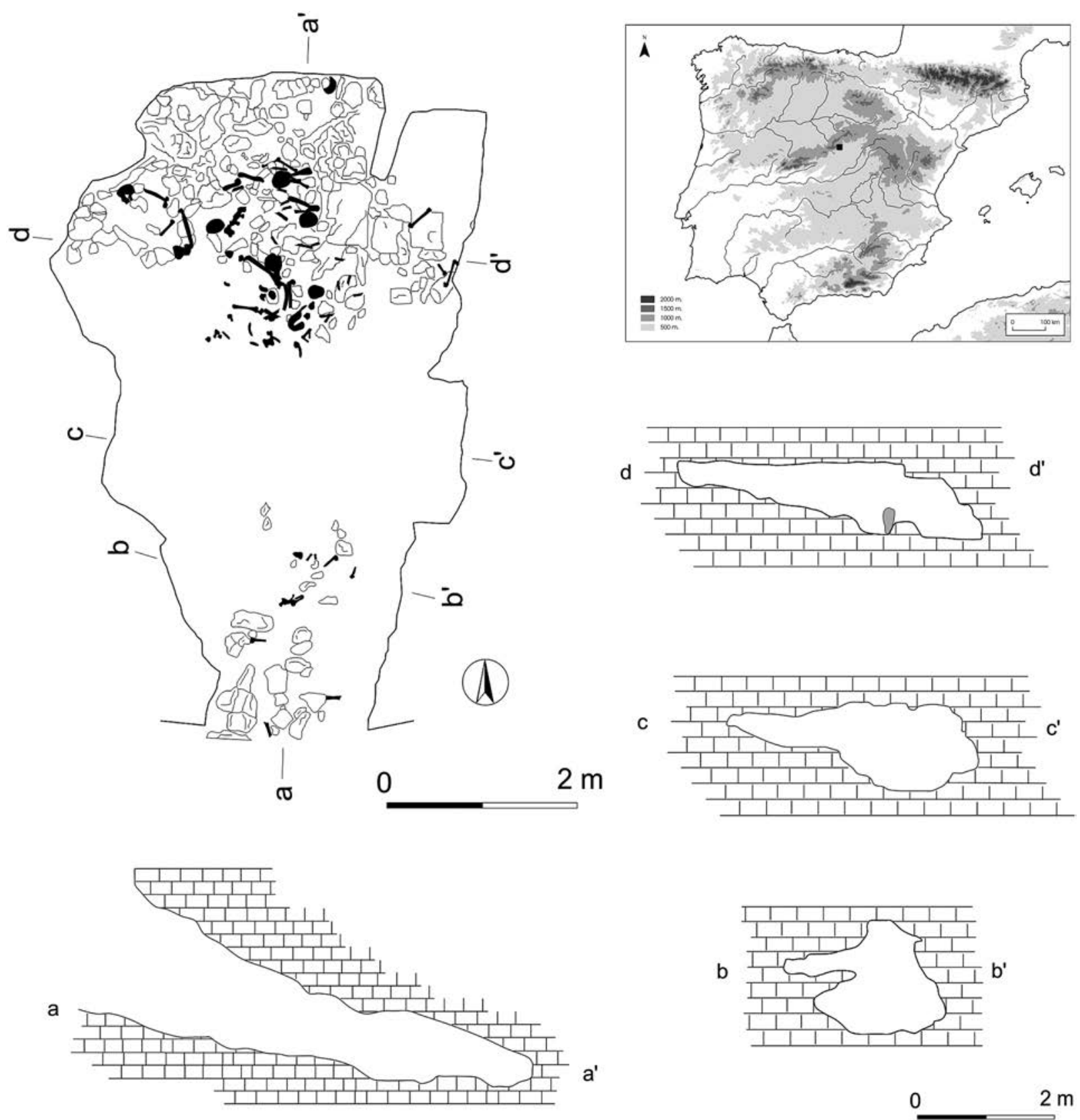

Fig. 1. Localización de El Rebollosillo (Torrelaguna, Madrid) en la Península Ibérica. Planimetría general con la distribución de los restos óseos humanos y secciones.

procedió a plantear y excavar consecutivamente otras 6 catas $\left(n^{\circ} 2,3,4,5,6\right.$ y 11) hasta llegar al límite marcado por la boca de la cavidad (Fig. 2). La práctica totalidad de las catas contaba con restos humanos muy fragmentados y dispersos, sin organización espacial alguna. Solo en el ángulo noroeste de la cata 2 se concentraban in situ, agrupados a modo de fardo, los restos completos de un brazo (húmero, cúbito y radio), así como fragmentos craneales de dos individuos, uno de ellos rodeado de piedras calizas de mediano tamaño. 


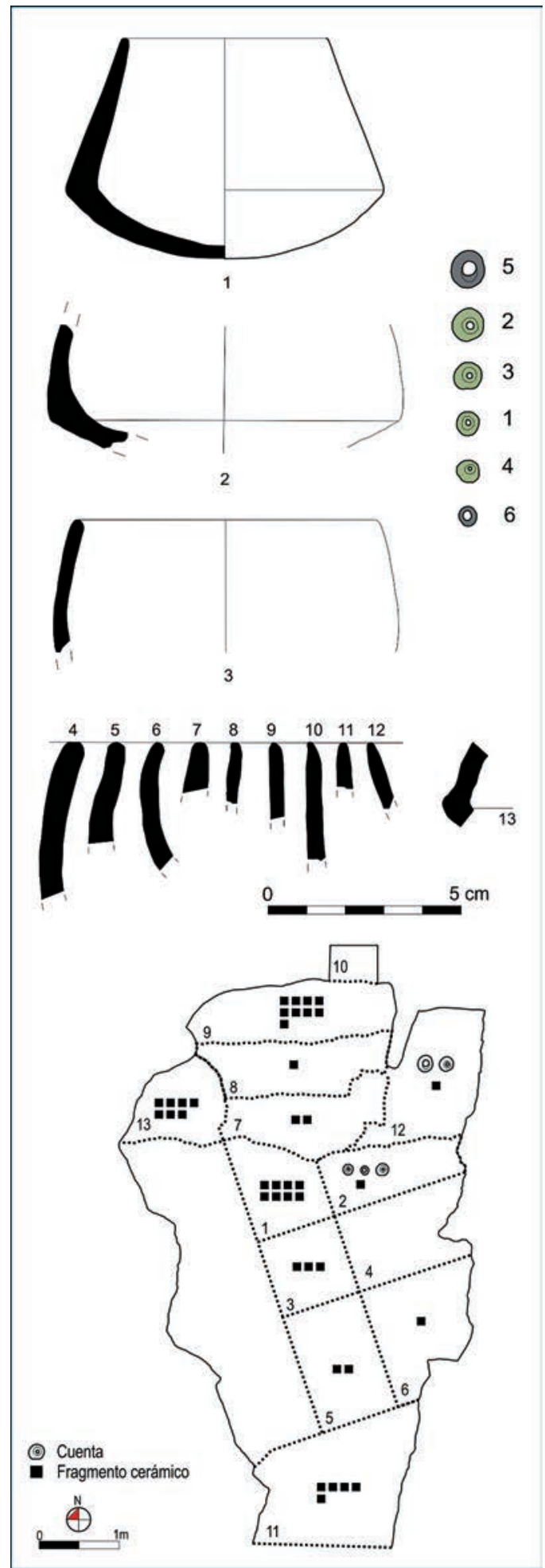

Fig. 2. Arriba, materiales recuperados en El Rebollosillo (Torrelaguna, Madrid) y abajo su distribución espacial por 'catas'.
La limpieza del perfil norte de la excavación permitió reconocer dos estratos claramente diferenciados. El superior, un estrato arcilloso, oscuro y muy plástico, ocupaba prácticamente desde la mitad del perfil hasta el techo calizo. El inferior, con una potencia máxima de $30 \mathrm{~cm}$, era clara continuación del sedimento arqueológico en el que se habían recuperado los restos humanos. El estrato superior indicaba que la sedimentación completa del karst fue posterior a su uso funerario y que, por tanto, la zona colmatada quizás fuera la mejor preservada del conjunto.

El estrato de colmatación, sin material arqueológico, se excavó horizontalmente (en mina) para acceder en planta al que contenía los restos prehistóricos. Para ello, dadas las dificultades del proceso, se abrieron 6 catas de planta irregular $\left(\mathrm{n}^{\circ}\right.$ 7 a 10, 12 y 13, Fig. 2), excavándose un total de $7,35 \mathrm{~m}^{2}$ nuevos de yacimiento que incrementaron la superficie de la cavidad a $22,5 \mathrm{~m}^{2}$.

La ampliación definió con claridad el proceso de formación del yacimiento. La zona preservada de enterramientos se disponía en el fondo de la cavidad, sobre la superficie calcárea. La planimetría general obtenida de la excavación de estas últimas catas (Fig. 1) permite hacerse una idea de cómo se depositaron los restos humanos antes de verse afectados por procesos posdeposicionales. Las sucesivas inhumaciones de porciones de individuos ya esqueletizados implicaron la remoción de rocas y sedimento, seguida por la excavación de una oquedad donde se depositaban los restos. Posteriormente se protegía algunos cráneos y una selección de huesos largos con fragmentos calizos de tamaño medio. Este procedimiento se utilizó para inhumar los restos parciales de al menos 6 individuos. De todos ellos, únicamente un fragmento de fémur y cadera se encontraban en conexión anatómica, dispuestos en el borde occidental de la cata 7 . Las características y distribución de los restos humanos, con una combinación de elementos dispersos sin conexión anatómica y otros intencionalmente agrupados en conjuntos, sugerían un programa mortuorio de manipulación secundaria de los cadáveres, sin que se constataran evidencias de dónde se pudo producir la esqueletización de los individuos.

Antes de estas acciones se hincaron verticalmente dos grandes lajas calizas, resultantes del derrumbe parcial del techo, para limitar el espacio 
funerario al sector occidental de la cavidad. Sobre ellas se acumuló un conjunto de rocas de mediano tamaño. Estos bloques cerraban el acceso a la conducción kárstica, que corría encajada en todo el sector oriental y que quizás estuvo temporalmente en funcionamiento durante el uso funerario de la cueva. La conducción se documentó con claridad en la cata 12 y afecta a $9,90 \mathrm{~m}^{2}$ de la superficie desde la boca hasta el límite noreste de la excavación. Dicha filtración fue encajándose y profundizando hacia el noreste de la cavidad, removilizando los posibles restos humanos depositados sobre ella. Su progresiva colmatación fue posterior al uso funerario del lugar, dado que sus sedimentos incluyen restos humanos, 13 fragmentos cerámicos prehistóricos y 4 de las 6 cuentas de collar recuperadas.

Tras este proceso una nueva fase de sedimentación cerró definitivamente el karst, sellando gran parte de los enterramientos. La cavidad no llegó a colmatarse por completo. El espacio de mayor amplitud se convirtió en refugio de pequeños mamíferos, roedores y algún que otro humano rastreable por dos fragmentos de cerámica contemporánea y un pequeño trozo informe de hierro recuperados en la cata 11 , dispuesta en la boca.

\section{CIRCUNSTANCIAS E INTEGRIDAD DE LA COLECCIÓN ANTROPOLÓGICA}

Tras finalizar la intervención los restos humanos y demás artefactos fueron adecuadamente etiquetados y depositados en los almacenes que la Comunidad de Madrid tenía por entonces en la Escuela Taller de Arqueología de Alcalá de Henares. Tras 10 años la colección fue trasladada a la sede actual del Museo Arqueológico Regional en dicha ciudad. Durante el proceso se etiquetaron de nuevo las bolsas que habían perdido su identificación contextual. Cuando, en junio de 2012, surge la posibilidad de abordar en profundidad el estudio antropológico, prácticamente el $25 \%$ de las bolsas carecían de etiqueta de identificación contextual.

Las catas originales en las que se dividió la excavación fueron la referencia para la observación macroscópica de los restos, la toma de medidas antropométricas y el cálculo fiable del Número

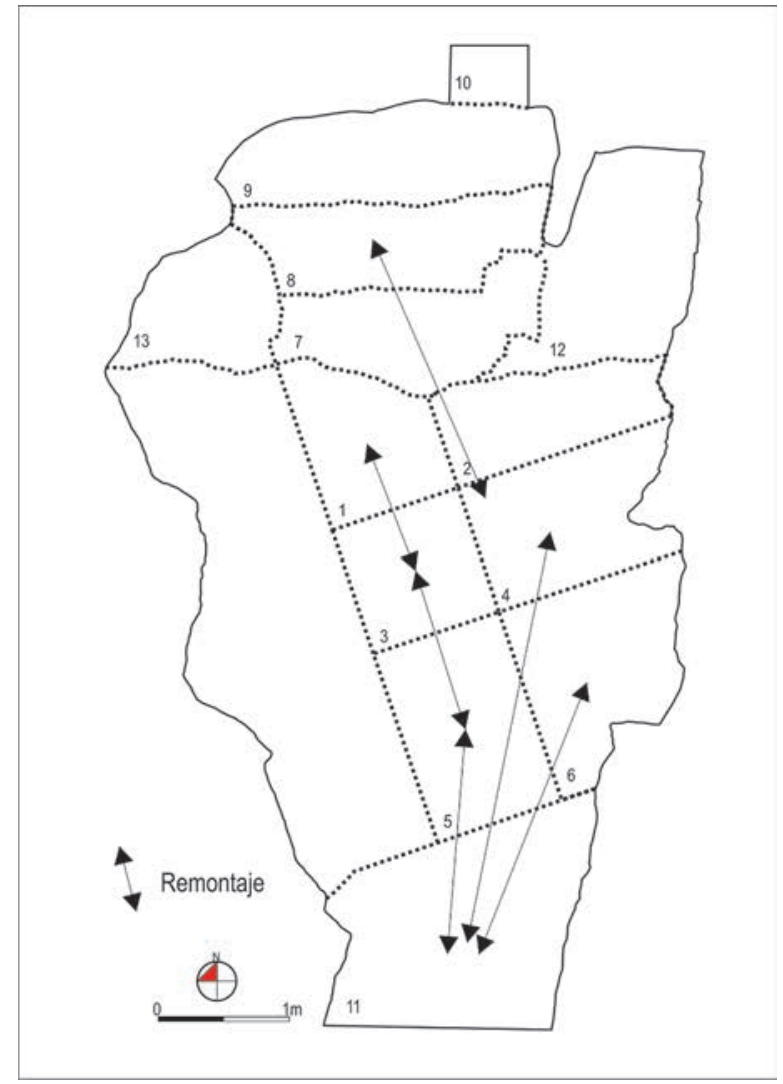

Fig. 3. Relación espacial de los remontajes de restos óseos humanos detectados en El Rebollosillo (Torrelaguna, Madrid).

Mínimo de Individuos (NMI). En cada una se intentó recomponer los restos partiendo de su posición original en la cueva. Una vez localizados los fragmentos pertenecientes al mismo hueso se buscaron los que pudieran estar en otras catas contiguas o no.

Como se observa en la figura 3 , a excepción de un húmero de un individuo adulto, los remontajes se limitan a las catas afectadas por la conducción del karst. Ello apoya la integridad relativa del registro excavado en las cuadrículas interiores de la cavidad.

Como el estudio del material requería su limpieza y reconstrucción parcial, antes de iniciarlo se seleccionaron para su potencial análisis isotópico $(\mathrm{C} 14, \mathrm{Sr}, \mathrm{O}) 16$ fragmentos que correspondían a 16 individuos: 2 infantiles, 1 juvenil, 13 adultos y otro al que no se pudo identificar con precisión como juvenil o adulto. Para ase- 


\begin{tabular}{|c|c|c|c|c|c|c|c|c|c|c|c|c|c|}
\hline M. \# & Ind. \# & Cata & Pieza & Edad & ${ }^{87} \mathrm{Sr} /{ }^{86} \mathrm{Sr}$ & $\delta^{13} \mathrm{C}_{\mathrm{ap}}$ & $\delta^{18} 0$ & $\delta^{13} \mathrm{C}_{\mathrm{c} 0}$ & $\delta^{15} \mathrm{~N}$ & $\mathrm{C}: \mathrm{N}$ & $\mathrm{C}^{14} \mathrm{BP}$ & $\delta^{13} \mathrm{C}_{\mathrm{c} 0}$ & Cal $2 \delta \mathrm{AC}$ \\
\hline 67 & 1 & 7 & temporal izq. & adulto & 0,70830 & & & & & & CNA4006 $4065 \pm 31$ & $-18,60$ & 2850 a 2480 \\
\hline 68 & 2 & Superf. & temporal der. & adulto & 0,70816 & & & & & & CNA4007 4004 \pm 31 & $-18,51$ & 2620 a 2460 \\
\hline 69 & 3 & s/e & temporal der. & infantil & 0,70811 & & & & & & CNA4008 $4005 \pm 30$ & $-16,30$ & 2580 a 2460 \\
\hline 70 & 4 & 12 & temporal izq. & infantil & 0,70808 & & & & & & CNA4009 3995 31 & $-19,52$ & 2580 a 2460 \\
\hline 71 & 5 & 8 & temporal der. & adulto & 0,70829 & & & & & & CNA2364 4015 \pm 35 & $-18,49$ & 2630 a 2460 \\
\hline 72 & 6 & 2 & temporal der. & adulto & 0,70810 & & & & & & CNA4010 3989 \pm 31 & $-19,58$ & 2580 a 2460 \\
\hline 73 & 7 & 7 & temporal der. & juvenil & 0,70828 & & & & & & CNA2365 4005 \pm 35 & $-18,54$ & 2620 a 2460 \\
\hline 74 & 8 & s/e & temporal der. & adulto & 0,70822 & & & & & & CNA4011 4007士31 & $-19,21$ & 2620 a 2460 \\
\hline 75 & 9 & 9 & temporal der. & adulto & 0,70817 & & & & & & CNA2366 4020 \pm 35 & $-18,37$ & 2630 a 2460 \\
\hline 76 & 10 & 7 & temporal der. & adulto & 0,70821 & & & & & & CNA4012 $4086 \pm 30$ & $-16,02$ & 2860 a 2490 \\
\hline 77 & 11 & 11 & temporal der. & adulto & 0,70846 & & & & & & CNA2367 3915 \pm 35 & $-19,06$ & 2490 a 2290 \\
\hline 78 & 12 & $\mathrm{~s} / \mathrm{e}$ & temporal der. & adulto & 0,70831 & & & & & & CNA4013 $4024 \pm 30$ & $-15,95$ & 2620 a 2470 \\
\hline 79 & 13 & 11 & temporal der. & adulto & 0,70863 & & & & & & CNA4014 $3774 \pm 30$ & $-16,22$ & 2300 a 2050 \\
\hline 80 & 14 & 7 & temporal izq. & adulto & 0,70815 & & & & & & CNA2368 $4000 \pm 35$ & $-19,42$ & 2620 a 2460 \\
\hline 81 & 14 & 7 & M2 der. max. & adulto & 0,70938 & $-10,4$ & $-3,1$ & & & & & & \\
\hline 82 & 15 & 2 & temporal izq. & adulto & 0,70898 & & & & & & CNA2369 $4020 \pm 35$ & $-17,88$ & 2630 a 2460 \\
\hline 83 & 15 & 2 & M2 der. max. & adulto & 0,70896 & $-10,9$ & $-4,4$ & & & & & & \\
\hline 84 & 16 & 13 & temporal der. & adulto & 0,70825 & & & & & & CNA2370 4090 \pm 35 & $-18,81$ & 2870 a 2490 \\
\hline 85 & 16 & 13 & M1 der. sup. & adulto & 0,70922 & $-11,3$ & $-2,5$ & & & & & & \\
\hline 97 & $*$ & 9 & Oryc. cuniculus & adulto & 0,70809 & $-8,8$ & $-1,6$ & $-19,1$ & 6,6 & 3,5 & & & \\
\hline 98 & $*$ & 9 & Vulpes vulpes & juvenil & 0,70819 & $-10,7$ & $-0,6$ & $-21,4$ & 4,4 & 3,3 & & & \\
\hline
\end{tabular}

Tab. 1. Resultados de los análisis isotópicos realizados sobre restos óseos humanos, de Oryctolagus y Vulpes de El Rebollosillo (Torrelaguna, Madrid). M Muestra; Ind Individuo; superf. Superficie; s/e Sin etiqueta; sup. Superior; max. Maxilar.

gurar que la muestra pertenecía a individuos diferentes se seleccionó el hueso más frecuente (temporal derecho) que identificaba el NMI en adultos. Cuando la reconstrucción del cráneo lo permitió, el hueso temporal izquierdo sustituyó al anterior como material para dataciones, para no destruir todos los huesos temporales derechos adultos de la colección. Si era posible se tomaba, además, un molar del individuo para análisis de dieta $\left(\delta^{13} \mathrm{C}_{\mathrm{ap}}\right)$ y movilidad ( $\mathrm{Sr}$ y $\left.\mathrm{O}\right)$ (individuos 14, 15 y 16, Tab. 1). La conexión del hueso maxilar que albergaba el molar con el hueso temporal permitía confirmar la reconstrucción y la pertenencia de los fragmentos al mismo individuo.

\section{CRONOLOGÍA}

Se han obtenido un total de 16 determinaciones radiocarbónicas (Tab. 1) correspondientes a 16 de los 21 individuos identificados en el análisis antropológico, de los que conocemos también sus valores de ${ }^{87} \mathrm{Sr} /{ }^{86} \mathrm{Sr}$. Las dataciones calibradas muestran una fuerte coherencia interna con 11 de ellas estadísticamente iguales. Las dos más recientes pertenecen a individuos recuperados en la cuadrícula 11 , la más próxima a la boca de la cueva, lo que reforzaría la relativa integridad tafonómica del conjunto. El modelado bayesiano de la secuencia completa $\left(A_{\text {model }}\right.$ : 77$)$ sugiere un uso funerario breve situado entre el $2620 \mathrm{y}$ el 
2430 cal AC (mediana de los valores) ${ }^{3}$, que pudo prolongarse de 120 a 200 años $(1 \sigma)$, algo acorde con otras evidencias materiales y espaciales recuperadas.

\section{LA POBLACIÓN HUMANA}

La observación de los restos antropológicos a partir de su posición con respecto a las cuadrículas en las que se dividió la excavación permitió valorar su compatibilidad estructural y anatómica, identificando los compatibles entre sí y reconstruyendo las unidades esqueléticas, contiguas o no en el momento de su recuperación.

\subsection{Preservación y alteraciones tafonómicas}

La preservación del material óseo recuperado es buena a pesar de la escasa potencia estratigráfica del depósito arqueológico abierto a los frecuentes y agresivos procesos postdeposicionales abióticos, bióticos y - sobre todo- antrópicos.

La muestra recuperada se compone de 2100 restos: $1225(58,3 \%)$ pertenecientes a individuos adultos y $875(41,7 \%)$ a no adultos. Del total, 903 $(43,0 \%)$ han podido ser identificados anatómicamente. Al primer grupo corresponden 651 (72,1\%) y al segundo $252(27,9 \%)$. El análisis antropométrico solo fue posible en 17 elementos completos, entre los que destacan 8 cráneos casi intactos.

En la colección había evidencias de exposición al fuego: un primer metatarso completo, un fragmento de diáfisis de radio de adulto, otro no identificable de un hueso largo y algunas falanges con coloración oscura en varias de sus caras. Los fragmentos de huesos quemados presentaban estrías superficiales. Las características de las mismas hacen pensar que se quemaron tras la esqueletización. Los huesos frescos quemados presentan estrías y fracturas perpendiculares al eje mayor del hueso, se fragmentan más y, además, el hueso se vuelve muy ligero y puede deformarse notablemente. En cambio el hueso seco quemado no se

\footnotetext{
${ }^{3}$ Los resultados del modelado, realizado con OxCal 4.2, son los siguientes: $2640 / 2580$ a $2460 / 2410$ cal AC $(1 \sigma), 2700 / 2510$ a $2470 / 2230$ cal AC $(2 \sigma)$.
}

contrae, si/no que se fractura en astillas, tomando como patrón el eje longitudinal del hueso. Además la reducción del peso es menor (Etxeberria 1993; Botella et al. 2000). Cuando la exposición al fuego ha sido accidental, los efectos del calor suelen quedar limitados al quemado superficial y ennegrecimiento de los huesos (Brothwell 1981). La distribución de los huesos quemados por gran parte de la cueva sugiere que la acción del fuego no es achacable a procesos posdeposicionales, por ejemplo, vinculados a hogueras encendidas tras los enterramientos de las que tampoco hay evidencia sedimentaria. Más bien es previsible que sucediera tras la esqueletización de los cadáveres y, quizás, antes de su traslado al interior de la cueva.

El efecto del fuego, intencionado o fortuito, se detecta ocasionalmente en el registro funerario del III milenio AC en la Península Ibérica, en contextos de enterramientos colectivos secundarios (Fernández-Crespo 2015; Silva et al. 2015: 12), similares al del Rebollosillo. En particular, en el entorno de la Meseta el uso del fuego en contextos funerarios de diversas cronologías es bien conocido, tanto en estructuras al aire libre como en el interior de cuevas (Kunst y Rojo 2002; Vidal 2013).

Además, en el Rebollosillo, se han reconocido escasos huesos con marcas producidas por roedores y mamíferos de pequeño tamaño, a pesar de que sus restos se han recuperado en gran número en la criba por agua de un muestreo de sedimentos. Esta escasa afección por parte de roedores sugiere que el proceso de colmatación de la cavidad se inició poco tiempo después de su uso funerario, lo que quizás limitó la accesibilidad de los restos óseos.

\subsection{Identificación del NMI}

El análisis ha establecido el siguiente NMI por categoría de edad: 2 individuos perinatales, 5 infantiles, 2 juveniles y 12 adultos. El NMI de los restos óseos de mayor tamaño se estimó a partir de la porción petrosa del hueso temporal. Corresponden a individuos juveniles ( $>12$ años) y adultos (>20 años). Gracias a la reconstrucción de fragmentos de huesos compatibles se reconocieron diez huesos petrosos completos pertenecientes a distintos temporales derechos y otros cuatro frag-

Trab. Prehist., 74, N. ${ }^{\circ}$ 1, enero-junio 2017, pp. 68-85, ISSN: 0082-5638

doi: $10.3989 /$ tp. 2017.12184 
mentos de temporal derecho incompatibles con los anteriores. Como resultado, se han identificado 14 individuos juveniles/adultos.

La estimación del NMI de los individuos subadultos ( $<12$ años) tuvo en cuenta las características del esqueleto y de la dentición. Se evaluó la frecuencia de aparición de determinados huesos, junto con sus incompatibilidades en tamaño y desarrollo biológico. Se identificaron los dos individuos perinatales a partir del tamaño de 2 huesos temporales derechos y 2 isquiones derechos. La discriminación de los 5 individuos infantiles atendió a las incompatibilidades de tamaño y lateralidad de 5 iliones y 5 primeros metatarsos. El NMI de la categoría de edad de individuos juveniles se ha estimado a partir de las incompatibilidades en el desarrollo entre un fémur izquierdo y una tibia izquierda que existen, al menos, en dos individuos pertenecientes a este grupo de edad.

\subsection{Estimación de la edad de muerte}

La identificación del NMI arroja información general sobre el número de individuos pertenecientes a los diferentes grupos de edad de la muestra recuperada. La desconexión de las unidades anatómicas y la gran variabilidad poblacional encontrada, incluso en cada grupo de edad, exigió diferentes metodologías para eliminar al máximo el posible error en dichas estimaciones. De forma preliminar se utilizaron los siguientes grupos de edad de muerte: perinatal (de 0 a 1 año), infantil (1 a 12 años), juvenil (12 a 20 años) y adulto ( $>20$ años). En los individuos adultos que preservaban la sínfisis púbica (2 individuos masculinos) se estimó la edad a partir de su morfología (Brooks y Suchey 1990) en los rangos entre 23-57 y 34-86 años.

La estimación de la edad de muerte de los individuos subadultos según las características de la dentición siguió la metodología propuesta por Ubelaker (1978), basada en el desarrollo y la calcificación dental, y por Liversidge et al. (1998), que considera la longitud del germen dental en calcificación. Además, se tuvo en cuenta el patrón de fusión de las epífisis de los huesos largos.

La metodología de Ubelaker (1978) pudo aplicarse a 60 piezas dentales. Las edades de los subadultos se estimaron entre los 6 meses \pm 3 meses y 15 años \pm 24 meses. Se identificaron once edades diferentes, muchas de ellas solapadas. Por ello se evaluó la posibilidad de que algunos dientes perteneciesen al mismo individuo y hubieran sido clasificados en varios estadios de crecimiento. Para establecer si existía más de un individuo en cada rango de edad se consideraron el número total de dientes, el tipo de dentición (de leche o permanente), la arcada (superior o inferior) y la lateralidad. Las edades estimadas por el segundo método resultaron similares a las obtenidas por el primero y con valores muy próximos entre sí. Esta continuidad en las edades calculadas impedía establecer límites claros, por lo que se excluyeron los resultados de este procedimiento para los subadultos.

Para estimar la edad fisiológica de los esqueletos inmaduros también se observó el aspecto y la unión de las epífisis a las diáfisis en algunos elementos óseos, así como la longitud de los huesos largos (Campillo y Subirà 2004). Estas edades también deben entenderse como estimadas (Baker et al. 2005) dado que existe una importante variabilidad interpoblacional en las edades de fusión y en el desarrollo del esqueleto. En los individuos perinatales la fusión del anillo timpánico en el hueso temporal se produce alrededor del octavo/ noveno mes de gestación. Su ausencia indicaría que la edad de estos individuos se correspondería con la estimada a partir de la dentición (i.e. menores de un año) (Scheuer y Black 2000). En los individuos infantiles, se identificaron cinco fragmentos de atlas atribuidos a cuatro individuos menores de 5 años considerando las edades de fusión y su lateralidad e incompatibilidades de desarrollo. Además, se identificaron un axis en proceso de fusión y una mitad izquierda del arco neural de otro aún sin fusionar al resto de estructuras que componen la vértebra. Como esa fusión ocurre aproximadamente entre los 4 y los 6 años (Baker et al. 2005) la pieza debe pertenecer a un individuo de menor edad.

Por último, en los 2 individuos juveniles se observó una sutura esfeno-occipital en proceso de fusión. Este cierre ocurre entre los 11 y los 16 años en individuos femeninos y entre los 13 y 18 en masculinos (Scheuer y Black 2000). La edad se estima por tanto entre los 11 y 18 años. Se identificaron además un radio y un ilion juveniles cuyo rango de variabilidad es compatible con el de las demás piezas que determinan el NMI de juveniles. 


\subsection{Determinación del sexo}

Solo se determinó el sexo sobre los individuos adultos que mostraban un marcado dimorfismo sexual. Se analizaron los siguientes caracteres morfológicos de los huesos coxales, tanto completos como reconstruidos: surco preauricular, escotadura ciática, arco compuesto, pelvis inferior y proporción isquiopúbica (Bruzek 2002). Su mala preservación limitó la aplicación del método a tres coxales, reconociendo 1 femenino y 2 masculinos.

\subsection{Patologías y otros caracteres de interés}

El 12,7\% de los 202 dientes estudiados presenta cálculo dental, pero la estimación puede verse afectada a la baja por el posible desprendimiento de los depósitos de calcio durante o tras la excavación. El 9\% de la muestra tiene caries: el 6\% con lesión en la línea amelocementaria, el 1,5\% en la cara oclusal y otro $1,5 \%$ en la corona. Un $22 \%$ son lesiones graves que alcanzan la pulpa del diente. El resto son lesiones superficiales o de gravedad media. En general la prevalencia de caries es leve o moderada, pudiendo indicar una dieta baja en hidratos de carbono, aunque también podría considerarse esta baja frecuencia como reflejo de la juventud de los individuos (Díaz-Zorita et al. 2009). El 42,3\% de las piezas cuentan con un desgaste dentario nulo o casi nulo; un $21,3 \%$ moderado y un 3,7 severo con exposición de la dentina de la cara oclusal. Finalmente, en una mandíbula un proceso patológico perfora el hueso a nivel del segundo incisivo de la hemimandíbula derecha, formando una cavidad irregular. Sin pretender hacer un diagnóstico diferencial de la lesión, se pueden citar como posibles orígenes tanto un quiste radicular o granuloma apical como una osteítis inespecífica, generalmente asociada a una reabsorción ósea y a la pérdida de la pieza dentaria (Campillo 2001), entre muchos otros posibles diagnósticos.

Se observan patologías del esqueleto axial y apendicular. Uno de los cráneos recuperados presenta fenómenos porosos localizados en el eurión del parietal izquierdo, en la zona media de la sutura lambdática derecha y en el occipital, en la región del opistocráneo. Sus características macroscópicas, sin engrosamiento aparente, descar- tarían la hipótesis de que se tratara de osteoporosis hiperostótica (Campillo 2001). Se consideró como alternativa que un tumor destructor de hueso en sus primeros estadios de desarrollo, pudiera haber originado un mieloma múltiple (Botella 2003). El diagnóstico diferencial de estos signos requeriría el examen directo de un especialista en este tipo concreto de patologías.

Se identificó también un fragmento de techo orbital de un individuo infantil con cribra orbitalia. Entre las etiologías descritas para su aparición, las más citadas son la anemia ferropénica adquirida por nutrición deficiente, mala absorción intestinal, pérdida de hierro por hemorragias, diarreas o infecciones (Carlson et al. 1974). Otros motivos podrían ser las anemias congénitas hemolíticas (talasemia, anemia falciforme, etc) (Campillo et al. 1990). Sin embargo, varios autores proponen una disminución gradual de la frecuencia de cribra orbitalia con la edad (Trancho et al. 1991). Sugieren un proceso evolutivo en los fenómenos porosos encontrados en la bóveda craneal y en otras partes del esqueleto por el cual unos tipos de porosidad darían lugar a otros.

Entre los huesos largos de la colección se identificó la porción diafisiaria de un cúbito subadulto, probablemente izquierdo, con marcadas alteraciones macroscópicas. Algunas son posdeposicionales y otras signos de aposición ósea a modo de 'capa de cebolla' compatibles con periostosis. El estudio radiológico confirmó su origen infeccioso, descartando otras posibles patologías traumáticas.

Una tibia infantil cuenta con una porosidad periostótica asociada a exostosis. Este fenómeno es característico de los individuos infantiles que han sufrido un proceso infeccioso (Ortner 2003). $\mathrm{Su}$ prevalencia en tibias es bastante frecuente: la incidencia de remodelaciones del periostio es mayor en los huesos de las extremidades inferiores.

Finalmente, se observan numerosos signos artrósicos en dos vértebras cervicales. Ambas tienen un gran desgaste en sus superficies de articulación, disco vertebral e interapofisarias, acompañado de una fuerte remodelación. Además, son marcadamente asimétricas como consecuencia de un aplastamiento lateral. En aquella donde la lesión es más notable, se advierte una eburnación con porosidad coalescente. También se identifican algunas vértebras lumbares aisladas con leves signos de eburnación y excrecencias óseas en forma de osteofitos. Estos signos artrósicos parecen ser 
consecuencia de la degeneración del cartílago articular y de las demás alteraciones que se derivan de este tipo de lesión. Estas patologías degenerativas en cervicales y lumbares son frecuentes dado que son las comúnmente más afectadas por la sobrecarga mecánica (Campo 2003).

Un rasgo interesante sin relación con procesos patológicos es el aplanamiento transversal (platicnemia) de la diáfisis de varias tibias de la colección. Generalmente se ha relacionado su aparición con factores patológicos y de desarrollo muscular $\mathrm{y}$, en concreto, con la adopción frecuente de una postura acuclillada (Brothwell 1981).

\subsection{Análisis de isótopos}

Se seleccionaron 19 muestras de 16 individuos para el análisis isotópico de estroncio, 16 sobre hueso y 3 sobre esmalte dental, así como dos restos de zorro y conejo (Tab. 1). Los isótopos de estroncio son incorporados a los tejidos de los seres vivos por medio de la ingesta de agua y alimentos. La historia geológica de una región y los tipos de rocas y sedimentos de su subsuelo pueden dar lugar a diferencias mensurables en las proporciones de estroncio biodisponibles en animales y vegetales. En este sentido, las muestras analizadas se situarían previsiblemente en un intervalo de ${ }^{87} \mathrm{Sr} /{ }^{86} \mathrm{Sr}$ próximo al agua marina $(0,709)$, dado que El Rebollosillo se sitúa en un contexto geológico de rocas carbonatadas cretácicas. Las posibles fuertes divergencias entre los valores isotópicos de los individuos enterrados y los valores regionales podrían por tanto interpretarse como evidencias de individuos provenientes de otras zonas.

El estroncio fue extraído en el laboratorio blanco del Department of Earth and Environmental Sciences de la University of Iowa utilizando resinas de intercambio iónico (Waight et al. 2002). Los ratios ${ }^{87} \mathrm{Sr} /{ }^{86} \mathrm{Sr}$ se obtuvieron procesando cada muestra en el espectrómetro de masas con plasma acoplado inductivamente $(M C$ ICP-MS) Nu Plasma $\mathrm{HR}^{4}$. Todos los valores fueron normalizados al valor estándar internacional

\footnotetext{
${ }^{4}$ Realizado en el del Departamento de Geología de la Universidad de Illinois bajo la supervisión del Dr. Craig Lundstrom.
}

NIST987 de 0.710268 , que tuvo una reproductibilidad de $\pm 0,000050$ ( 2 d.e., $\mathrm{n}=91)$.

La composición de Sr local para los enterramientos conocidos del área de Madrid está actualmente entre los valores de 0,707 y 0,713 . Este rango ha sido calculado a partir del análisis de una amplia colección de muestras de enterramientos humanos de la Prehistoria reciente de la región de Madrid (Waterman et al. 2014; Díaz-del-Río et al. 2017). Como sugieren Bentley y otros (2004), hemos definido el intervalo de variación isotópica regional utilizando 2 desviaciones estándares de la media de todos los valores humanos analizados $(\mathrm{n}=85)$. Además, se analizaron un total de 14 muestras de fauna (Erinaceus europaeus, Oryctolagus cuniculus, Lepus sp., Felis catus, Vulpes vulpes, Canis familiaris, ovis/capra, Sus sp.) con el objeto de ayudar a calibrar el rango regional. Los valores de ${ }^{87} \mathrm{Sr} /{ }^{86} \mathrm{Sr}$ de estas muestras se sitúan entre 0,7125 y 0,7080 .

Todos los valores isotópicos de ${ }^{87} \mathrm{Sr} /{ }^{86} \mathrm{Sr}$ obtenidos para los individuos muestreados de El Rebollosillo se concentran en la franja baja del rango local para la región de Madrid (0,708-0,793). El test de Grubbs (1969) confirma la ausencia de valores anómalos ${ }^{5}$. En consecuencia, no se identificaron individuos no locales entre los analizados utilizando esta metodología. Los ratios de ${ }^{87} \mathrm{Sr} /{ }^{86} \mathrm{Sr}$ más divergentes por mostrar los valores más altos de todas las muestras proceden del esmalte dental de tres individuos uno de los cuales exhibió el valor más elevado sobre hueso. Las 13 muestras restantes corresponden a los únicos cráneos asignables con seguridad a diferentes individuos. La agrupación de los valores sobre hueso y la divergencia entre las muestras sobre esmalte y hueso previsiblemente reflejan la diagénesis del hueso, cuyo carbonato quedó impregnado de los valores de estroncio local procedentes del sedimento donde estaba enterrado. Por lo tanto, es posible - aunque no probable, dado el resto de los resultados regionales (Díaz-del-Río et al. 2017) que existieran firmas isotópicas no locales enmascaradas por el hueso contaminado.

Se obtuvieron valores de $\delta^{13} \mathrm{C}$ y $\delta^{18} \mathrm{O}$ adicionales para los tres individuos cuyo esmalte fue muestreado. Los análisis fueron realizados en el Laboratory for Archaeological Science de la Uni-

\footnotetext{
${ }_{5}$ Muestra $=19 ;$ Media $=0.7083 ; \mathrm{DE}=0.0004 ;$ Posible valor atípico $=0,7092 ; \mathrm{ESD}[Z]=2,5647$; Test de Grubb $=0.0863$
} 
versity of South Florida (Tykot 2004). Aunque variables, los valores de $\delta^{18} \mathrm{O}(-3.1,-4.4,-2.5)$ descartan un consumo habitual de recursos de agua de origen no local. Ello refuerza los resultados de $\mathrm{Sr}$ que sugieren el carácter mayoritariamente local de las poblaciones analizadas.

Como omnívoros, los valores teóricos de $\delta^{13} \mathrm{C}_{\mathrm{ap}}$ para humanos en ecosistemas dominados por plantas $\mathrm{C}_{3}$ se sitúa aproximadamente en torno al $-14 \%$, frente a los valores próximos a $\sim 0 \%$ en ecosistemas $\mathrm{C}_{4}$. Aquellos valores intermedios sugieren entornos y dietas mixtas (Lai 2008; Tykot et al. 2009; Kohn y Cerling 2002). Los escasos resultados de isótopos estables de carbono de humanos del Rebollosillo muestran valores de $\delta^{13} \mathrm{C}_{\text {ap }}$ de $-10,4,-10,9$ y $-11,3 \%$, sugiriendo un ligero enriquecimiento en comparación con los valores teóricos para ecosistemas $\mathrm{C}_{3}$, como es el caso. Es difícil valorar hasta qué punto este somero enriquecimiento es resultado del consumo de plantas $\mathrm{C}_{4}$ (o CAM), sean mijos u otras plantas locales (e.g. la verdolaga, Tankersley et al. 2016) o de factores externos (e.g. la pluviosidad, Lai 2008: 207), dada la limitada muestra y la falta de valores de $\delta^{13} \mathrm{C}_{\mathrm{co}}$ para estos mismos individuos. Fernández-Crespo y otros (2017: 331) han sugerido que la aridez mostrada por el registro paleoambiental puede estar detrás de valores enriquecidos como los documentados en la Motilla de Azuer (Nájera et al. 2010), similares a los del Rebollosillo, aunque la muestra es todavía insuficiente para un análisis estadísticamente robusto de los posibles efectos en el tiempo de la variable climática a escala peninsular.

\section{MATERIALES}

Las minúsculas cantidades de artefactos recuperados en El Rebollosillo contrastan con la cantidad y variedad de restos habituales en la mayoría de las cuevas sepulcrales contemporáneas de la Península Ibérica (p.ej. Jordá y Mestres 1999; Soler 2002; Gonçalves 2008; Soler et al. 2016). El conjunto se compone de 43 fragementos cerámicos y 6 cuentas de collar. No hay industria ósea, ni lítica, pulida o tallada (Fig. 2).

Los descubridores del conjunto recuperaron el único cuenco completo. Los 42 fragmentos cerámicos proceden de la excavación y son muy pequeños: la media de las dimensiones máximas

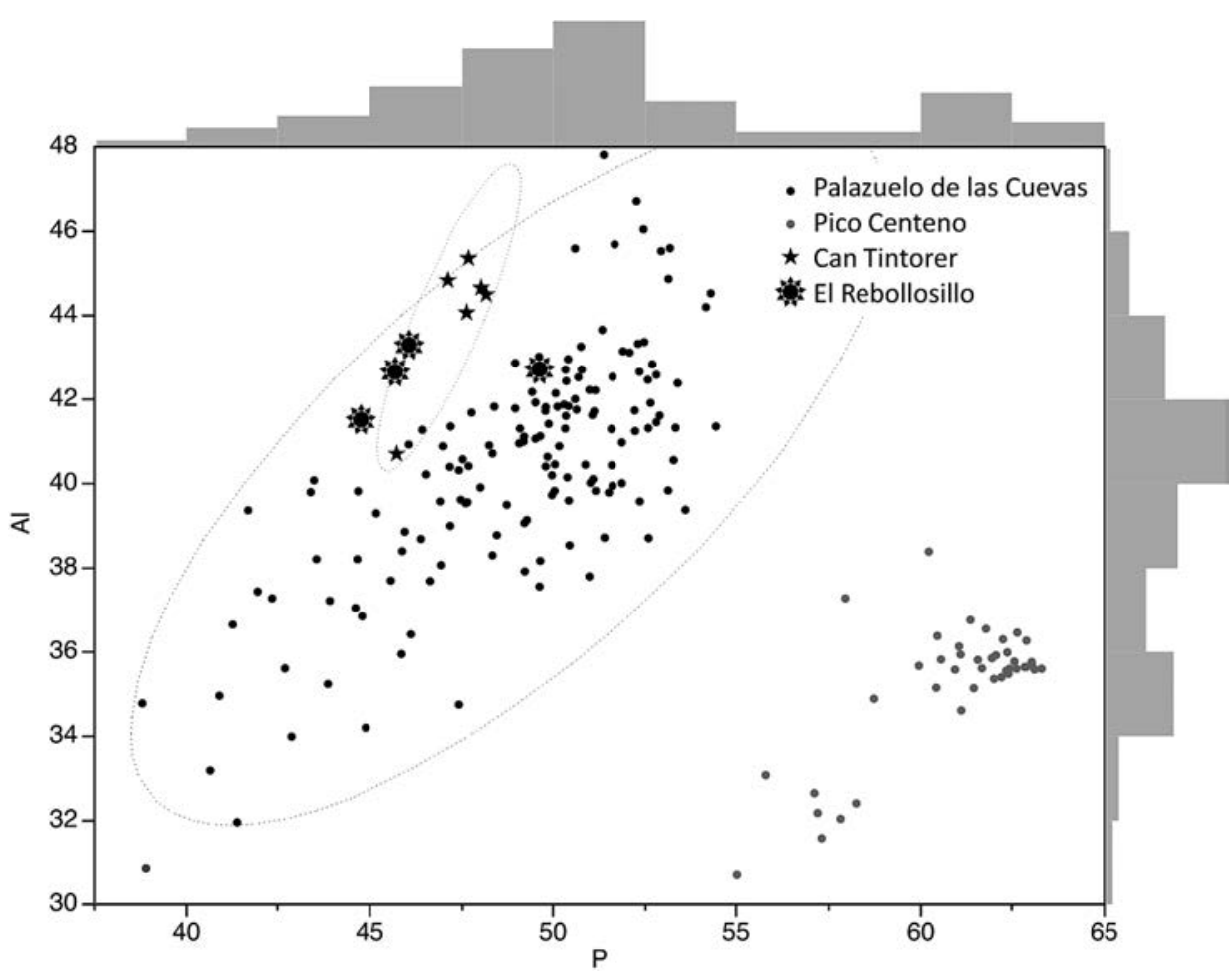

Fig. 4. Composición elemental de las cuentas de collar recuperadas en El Rebollosillo (Torrelaguna, Madrid) comparada con la composición de la variscita de las minas explotadas durante la Prehistoria en la Península Ibérica. Cociente P/Al.

Trab. Prehist., 74, N. ${ }^{\circ}$ 1, enero-junio 2017, pp. 68-85, ISSN: 0082-5638

doi: $10.3989 /$ tp. 2017.12184 
es de 2,4 cm; sólo el 10\% supera los $4 \mathrm{~cm}$ y el $47 \%$ tiene entre 2 y $1 \mathrm{~cm}$. La ausencia de piezas menores es un probable resultado de cribar en seco sedimentos muy arcillosos. Sin embargo, por lo general, los restos están poco erosionados, lo que sugiere que fueron incorporados al yacimiento ya fragmentados y no han sufrido procesos postdeposicionales intensos. Tanto las 13 piezas orientables como la homogeneidad en los espesores de la totalidad de los fragmentos $(0,57 \mathrm{~cm}$ de media) indican que la mayoría corresponden a cuencos de pequeño tamaño. De nuevo, la evidencia apunta a un proceso de recogida selectiva de restos, tanto humanos como materiales, tras una fase de inhumación o exposición previa. El que todos los hallazgos se concentren sobre todo en las cuadrículas interiores de la cueva indica que son las menos afectadas por alteraciones posdeposicionales.

Las 6 cuentas de collar probablemente corresponden al mismo adorno personal, quizás pertenecientes al 'homo 2' cuyo cráneo fue recuperado en la 'cata 2'. La posible asociación se apoya en la recuperación de la cuenta 6 en el interior de dicho cráneo, la 1 en la misma cata y las 2 y 5 en el sedimento inmediato de la cata norte contigua ${ }^{6}$. Su clasificación mineralógica y análisis de procedencia se ha basado en los datos composicionales obtenidos con un equipo de fluorescencia de rayos X Oxford Instruments XMET7500 que monta un tubo de Rh, un detector SDD (silicon drift detector) y un cargador automático de 5 filtros. Para su análisis se han seguido criterios expuestos en otro lugar para la identificación positiva entre la composición elemental de la cuenta y la fuente geológica (Odriozola et al. 2010; Odriozola 2015).

Según la composición elemental de las 6 cuentas de collar analizadas (Tab. 2) las 4 cuentas de color verde (números 1 a 4) se corresponden con aluminofosfatos, en concreto con variscita. El origen más probable para este mineral, según se desprende del cociente atómico $\mathrm{P} / \mathrm{Al}$ que se ubica dentro de la elipse de confianza al $95 \%$, está en Palazuelo de las Cuevas (Aliste, Zamora). Los valores están muy cercanos a los de Can Tintorer (Gavá, Barcelona) (Fig. 4). Contrariamente, en la estimación del kernel de densidades no paramétrico de los valores del cociente $\mathrm{P} / \mathrm{Al}(\mathrm{n}=204)$

\footnotetext{
${ }^{6}$ Las cuentas 3 y 4 fueron recuperadas durante la limpieza inicial de la superficie previa intervención.
}

se puede deducir que los valores de El Rebollosillo se ubican en una zona de solape de las distribuciones de Palazuelo de las Cuevas y Can Tintorer. El gráfico ternario $\mathrm{Cr}-\mathrm{V}-\mathrm{Fe}$ (Querré et al. 2008) sugiere el primero como la procedencia más probable.

La clasificación mineralógica mediante la composición elemental de las dos cuentas de color negro es más complicada, debido a la gran cantidad de mineralogías utilizadas en la elaboración de elementos de adorno personal durante la Prehistoria Reciente (Domínguez Bella 2012). Como se aprecia en la tabla 2, la cuenta 6 sería clasificable como silicato magnésico, talco $\left[\mathrm{Mg}_{3} \mathrm{Si}_{4} \mathrm{O}_{10}(\mathrm{OH})_{2}\right]$ (Roberts et al. 1990; Deer et

\begin{tabular}{|c|c|c|c|c|c|c|}
\hline Elemento & R 1 & R 2 & R 3 & R 4 & R 5 & R 6 \\
\hline $\mathrm{Al}$ & 24.78 & 24.53 & 24.97 & 23.59 & 3.33 & 1.69 \\
\hline $\mathrm{Si}$ & 2.74 & 4.35 & 1.63 & 4.72 & 8.39 & 26.03 \\
\hline $\mathrm{P}$ & 30.27 & 30.16 & 33.29 & 29.19 & 0.2 & - \\
\hline S & 0.24 & 0.37 & 0.21 & 0.14 & 1.02 & 0.12 \\
\hline $\mathrm{Cl}$ & 1.96 & 1.94 & 1.45 & 2.42 & 2.58 & 0.99 \\
\hline K & - & - & - & - & 0.65 & - \\
\hline $\mathrm{Ca}$ & 0.39 & 0.37 & 0.71 & 0.39 & 42.31 & 0.1 \\
\hline $\mathrm{Ti}$ & 0.11 & 0.03 & 0.18 & 0.19 & 0.15 & - \\
\hline V & - & 0.15 & 0.17 & 0.09 & - & - \\
\hline $\mathrm{Cr}$ & 0.36 & 0.31 & 0.88 & 0.52 & - & - \\
\hline $\mathrm{Mn}$ & - & - & - & - & 0.05 & 0.01 \\
\hline $\mathrm{Fe}$ & 2.49 & 0.44 & 1.02 & 1.26 & 0.76 & 0.93 \\
\hline $\mathrm{Ni}$ & - & - & - & - & 0.01 & - \\
\hline $\mathrm{Cu}$ & - & - & - & - & 0.22 & - \\
\hline $\mathrm{Zn}$ & - & - & - & - & 0.01 & - \\
\hline As & 0.06 & 0.01 & 0.03 & 0.01 & - & - \\
\hline $\mathrm{Rb}$ & - & - & - & - & 0.01 & - \\
\hline $\mathrm{Sr}$ & - & - & - & - & 0.15 & - \\
\hline $\mathrm{Zr}$ & - & - & 0.01 & 0.01 & 0.02 & - \\
\hline Mo & - & 0.01 & 0.01 & - & 0.02 & - \\
\hline $\mathrm{Ag}$ & - & - & - & - & 0.04 & - \\
\hline $\mathrm{Cd}$ & - & - & 0.01 & - & - & - \\
\hline $\mathrm{Sn}$ & 0.01 & - & 0.01 & - & 0.04 & - \\
\hline $\mathrm{Ta}$ & 0.01 & 0.01 & 0.01 & 0.02 & - & - \\
\hline
\end{tabular}

Tab. 2. Composición elemental de las 6 cuentas de collar (R) recuperadas en El Rebollosillo (Torrelaguna, Madrid). 
al. 1992). En cambio la 5 sería un (Ca-Al), un silicato con un alto contenido en $\mathrm{Cl}$. Se propone un origen local para ambas.

\section{CARACTERIZACIÓN DEL ENTERRAMIENTO}

La distribución espacial y el tratamiento individualizado de algunos de los conjuntos óseos llevó a interpretar inicialmente el enterramiento como secundario, secuencial y colectivo. Esta interpretación, previa al estudio bioantropológico, valoraba la práctica ausencia de conexiones anatómicas (sólo una documentada), la distribución frecuentemente caótica de gran parte de los restos frente al claro reordenamiento y tratamiento diferencial de cráneos y determinados huesos largos, así como la extrema fragmentación de los posibles ajuares cerámicos que previsiblemente acompañaron a los individuos en una fase de descarnado previo (Díaz-del-Río 1996: 199).

Se podría describir un enterramiento secundario como aquel donde la desaparición de los tejidos blandos ocurre de forma activa (e.g., descarnamiento) o pasiva (e.g., decaimiento o degradación), antes del depósito definitivo de los restos óseos en un lugar distinto, o no, al del depósito primario.
En el registro osteoarqueológico, los enterramientos secundarios, ya sean simultáneos o no, suelen mostrar características concretas. Éstas pueden ser marcas de descarnación activa de restos óseos (indicativas de una acción de separación de tejidos blandos previa al enterramiento), o la falta de conexiones anatómicas entre los elementos óseos recuperados (evidencia directa de la remoción de los huesos). Si los esqueletos están incompletos podríamos hablar de un enterramiento secundario, ya que la proporción de huesos que cabría esperar no es la que se halla in situ. Estas ausencias de elementos concretos del esqueleto pueden estar relacionadas con la "selección" intencionada de ciertas piezas, con su pérdida por destrucción, transporte $\mathrm{u}$ otros factores tafonómicos. La persistencia de conexiones anatómicas en algunos esqueletos podría relacionarse con articulaciones más resistentes a la degradación, como sucede con la articulación coxofemoral entre otras, que aún debían seguir unidas por los ligamentos cuando se producía el depósito definitivo (Duday 1997). En El Rebollosillo, se ha encontrado una proporción de huesos pequeños muy inferior a la mitad de la esperable en la mayoría de los casos fueran o no adultos (Tab. 3). La única conexión anatómica (ya identificada durante la excavación, Díaz-del-Río 1996) corresponde a un coxal y un fémur izquierdo que, por su análisis preliminar, pertenecerían al mismo

\begin{tabular}{|l|c|c|c|c|c|c|}
\hline \multirow{2}{*}{} & \multicolumn{3}{|c|}{ Adultos } & \multicolumn{3}{c|}{ No-adultos } \\
\cline { 2 - 7 } & Observados & $\mathbf{\%}$ & Esperados (100\%) & Observados & $\mathbf{\%}$ & Esperados (100\%) \\
\hline Atlas & 2 & $17 \%$ & 12 & 0 & $0 \%$ & 9 \\
\hline Axis & 6 & $50 \%$ & 12 & 1 & $11 \%$ & 9 \\
\hline Cervicales & 20 & $24 \%$ & 84 & 25 & $40 \%$ & 63 \\
\hline Dorsales & 32 & $22 \%$ & 144 & 14 & $13 \%$ & 108 \\
\hline Lumbares & 17 & $28 \%$ & 60 & 6 & $13 \%$ & 45 \\
\hline Sacrales & 22 & $37 \%$ & 60 & 7 & $16 \%$ & 45 \\
\hline Carpos & 22 & $23 \%$ & 96 & 1 & $1.4 \%$ & 72 \\
\hline Tarsos & 37 & $62 \%$ & 60 & 2 & $4.4 \%$ & 45 \\
\hline Metacarpos & 3 & $2.5 \%$ & 120 & 26 & $29 \%$ & 90 \\
\hline Metatarsos & 49 & $41 \%$ & 120 & 26 & $29 \%$ & 90 \\
\hline Falanges & 84 & $13 \%$ & 672 & 47 & $9 \%$ & 504 \\
\hline
\end{tabular}

Tab. 3. Frecuencias observadas, esperadas y ausentes para los huesos de menor tamaño de El Rebollosillo (Torrelaguna, Madrid). Metatarsos, excepto astrágalo y calcáneo; falanges incluyen mano y pie.

Trab. Prehist., 74, N. ${ }^{\circ}$ 1, enero-junio 2017, pp. 68-85, ISSN: 0082-5638

doi: $10.3989 /$ tp.2017.12184 
individuo. A la vista de estos datos, se podría inferir que se trata de un enterramiento secundario y colectivo, donde la ausencia de elementos anatómicos está seguramente relacionada con la desconexión intencionada por acción antrópica (en el pasado y/o contemporánea). Prueba de ello es también el claro reordenamiento y tratamiento diferencial de algunos restos, en particular los cráneos, todos ellos sin mandíbula asociada.

La falta de evidencias de exposición a la intemperie y de marcas de descarnado, así como las escasísimas huellas de los efectos del fuego o de marcas producidas por roedores y mamíferos de pequeño tamaño sugieren que los restos humanos no estuvieron exhibidos durante el proceso de esqueletización. A su vez, es imposible saber si este proceso se produjo en el entorno inmediato del yacimiento o en otro lugar, aunque la pérdida de restos óseos y de cultura material favorece la segunda opción. De hecho, la cada vez más frecuente documentación de enterramientos "revueltos", "removidos" o "expoliados" en el contexto de yacimientos habitacionales del interior peninsular (p. ej. Flores y Garrido 2014; Liesau et al. 2014) quizás deba vincularse a este tipo de programa funerario.

El Rebollosillo fue un lugar colectivo de enterramiento, en el que se depositaron todos los rangos de edad de ambos sexos, quizás individuos vinculados por algún tipo de parentesco, ficticio o real. Sin embargo, el registro sugiere que sólo los adultos recibieron un tratamiento claramente individualizado, mediante la disposición cuidadosa del cráneo. Hasta lo que nos permite reconocer la estratigrafía, el depósito de cada uno de los individuos fue el resultado de una acción independiente. En definitiva, se trata de un espacio colectivo en el que intencionalmente se destaca el tratamiento individualizado de la persona. Con todas las cautelas necesarias, el hecho que todos los individuos documentados que recibieron este tratamiento fuesen adultos sugiere una práctica diferencial, quizás vinculada a un estatus adquirido con la edad.

\section{VALORACIÓN}

El estudio de la cueva sepulcral del Rebollosillo ha identificado un número mínimo de 21 individuos enterrados entre el 2620 y el $2430 \mathrm{cal}$

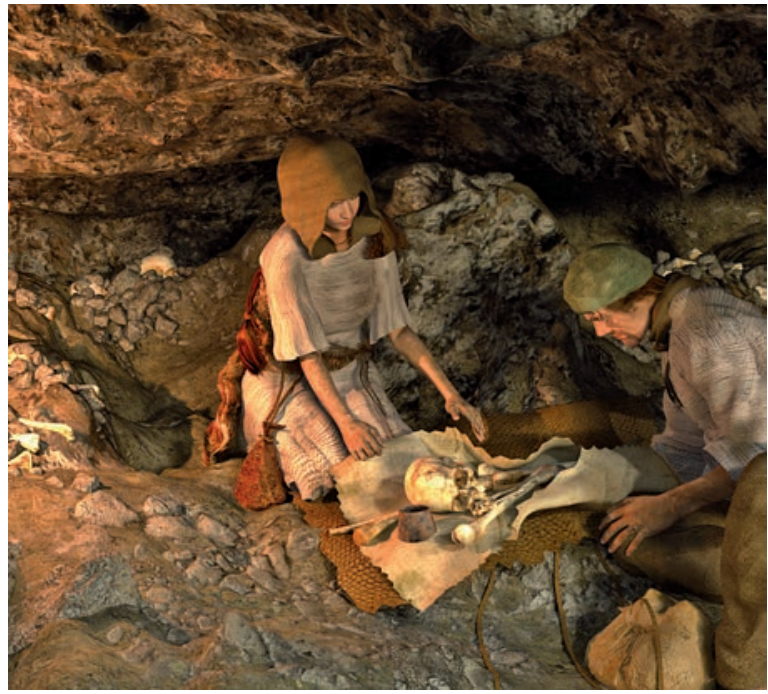

Fig. 5. Recreación de un enterramiento secundario en El Rebollosillo (Torrelaguna, Madrid). Detalle de la ilustración de Pilar Cienfuegos en Consuegra y Díaz-del-Río (2013: 63). Reproducción cortesía de la Dirección General de Patrimonio Cultural, Oficina de Cultura y Turismo de la Comunidad de Madrid (en color en la edición electrónica).

AC. En términos comparativos, es la tercera mayor colección de restos humanos documentados en un único enterramiento colectivo de la prehistoria regional tras las de El Perdido (Madrid) (Heras et al. 2014) y la Cueva 3 del Valle de las Higueras (Toledo) (Bueno et al. 2005). Es, además, el contexto funerario colectivo mejor datado de la Meseta hasta la fecha, con el 76\% del NMI identificados datados.

Nuestro análisis ha permitido definir una práctica funeraria de mediados del III milenio $\mathrm{AC}$ que probablemente representa el momento final de un programa mortuorio en varias etapas (Fig. 5). En este programa ningún grupo de edad o sexo queda excluido, aunque los adultos reciben un tratamiento individualizado. Todos ellos quedan finalmente despojados de los restos materiales, adornos personales y otros elementos previsiblemente vinculados al ritual previo a la esqueletización, que son incorporados en un estado fragmentario durante el último estadio del proceso. No es descartable que el proceso de esqueletización se produjese en la propia cueva, o inmediatamente junto a ella, pero carecemos de evidencias materiales para apoyar dicha interpretación. Al contrario, la propia disposición 
de los huesos, la exigua superficie practicable y la elevadísima fragmentación y escasez de la cultura material nos permiten proponer que los restos fueron probablemente trasladados desde otros lugares. Si nuestra interpretación fuese correcta, deberían documentarse las primeras etapas de dicho programa mortuorio en otros lugares contemporáneos, quizás en los propios lugares de habitación. De hecho, algunas de las más recientes evidencias regionales recuperadas en yacimientos de estas cronologías sugieren que la manipulación de cadáveres en distintos momentos de su proceso de esqueletización fue una práctica relativamente frecuente durante la segunda mitad del III milenio AC (Flores y Garrido 2014; Liesau et al. 2014).

En la última década ha aumentado de manera exponencial el registro funerario del III y II milenios AC en el centro de la Península Ibérica (Aliaga 2014; Pérez-Villa 2015). Como era previsible, y como refuerza el estudio de El Rebollosillo, este incremento cuantitativo ha venido de la mano de una acentuación de la variabilidad, tanto en las formas de los continentes funerarios como en la cantidad y organización espacial de los contenidos (Bueno et al. 2005; Liesau y Blasco 2015; Liesau et al. 2015).

Visto desde la perspectiva temporal que nos ofrece la ya sustancial colección de dataciones radiocarbónicas para la Meseta sur (Balsera et al. 2015a; Balsera et al. 2015b y anexos; www. idearqueologia.org), hay una evidente eclosión de múltiples manifestaciones funerarias a partir del $2600 \mathrm{cal}$ AC, en paralelo al paulatino abandono de la mayoría de los recintos de fosos datados, cuya construcción parece decaer hasta casi desaparecer a partir del 2450 cal AC (Fig. 6). El incremento de las manifestaciones funerarias continúa tras el 2200 cal AC, fecha canónica de inicio de la Edad del Bronce, conectado con una reducción de esta variabilidad a favor del enterramiento individual en hoyo. Esta tendencia general sugiere que la arena de la negociación política se deslizó gradualmente de los espacios colectivos hacia los programas mortuorios, de la acción colectiva coordinada a la paulatina implicación de unidades sociales crecientemente menores. En este contexto regional de ruina de los linajes (Gilman 2001) cobra sentido la incorporación en las prácticas sociales de los variados materiales asociados al "fenómeno" campaniforme.

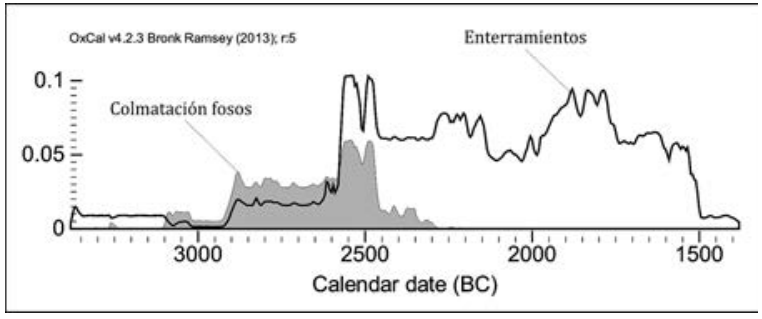

Fig. 6. Suma de probabilidades de las dataciones radiocarbónicas de colmataciones de recintos de fosos y de enterramientos de la Meseta sur (datos en Balsera et al. 2015a).

A lo largo de esta secuencia no se manifiesta un patrón claro de incremento o reducción en los niveles de gasto en los programas mortuorios, sea respecto al continente o al contenido asociado a los distintos individuos. La dificultad de sistematizar la "variabilidad indómita" 7 del registro funerario asociado a elementos campaniformes y sus contemporáneos en la Meseta sur es un claro ejemplo de ello. Esta variabilidad del registro arqueológico indica que la incorporación de objetos cerámicos, líticos o metálicos a los enterramientos, sean individuales o múltiples, masculinos o femeninos, sucede sin un evidente patrón espacial o temporal (Liesau y Blasco 2015), una pauta acorde con la previsible en una sociedad en la que predomina el estatus adquirido.

El registro funerario de la segunda mitad del III milenio AC en la Meseta se resiste a ser formalizado en normas pautadas de conducta. Resulta obvio que no se observan cambios bruscos, sino una reorganización permanente -quizás ad hoc- de prácticas sociales que se prolongan en el tiempo. En este sentido, sugerimos que la valoración combinada y detallada de los patrones funerarios y de las tendencias del registro en su conjunto muestra un camino más fructífero para entender el pasado.

\section{AGRADECIMIENTOS}

Nuestro reconocimiento a las aportaciones y colaboración de Manuel Campo Martín y Luis Moreno Estefanell (Universidad Autónoma de

\footnotetext{
${ }^{7}$ Parafraseando a Liesau y Morales (2012: 123).
}

Trab. Prehist., 74, N. ${ }^{\circ}$ 1, enero-junio 2017, pp. 68-85, ISSN: 0082-5638

doi: $10.3989 /$ tp.2017.12184 
Madrid), Ángel Minaya Vaquero (UCM), Enrique Baquedano, Antonio Dávila y Miguel Contreras (Museo Arqueológico Regional de la Comunidad de Madrid), así como las detalladas y constructivas críticas de los evaluadores, que han permitido mejorar sustancialmente el manuscrito inicial. Dedicamos una especial mención a Eduardo Penedo Cobo, que compartió con uno de nosotros (PDR) la responsabilidad de la excavación y documentación del yacimiento hace 28 años.

\section{BIBLIOGRAFÍA}

Aliaga, R. 2014: Sociedad y mundo funerario en el III y II milenio a.C. en la región del Jarama. British Archaeological Reports International Series 2630, Archaeopress. Oxford.

Baker, B. J.; Dupras, T. L. y Tocheri, M. W. 2005: The osteology of infants and children. University anthropology series 12, Texas A\&M University Press. College Station. Texas.

Balsera, V.; Bernabeu, J.; Costa-Caramé, M.; Díazdel-Río, P.; García Sanjuán, L. y Pardo, S. 2015a: "The radiocarbon chronology of Southern Spain's Late Prehistory (5600-1000 cal BC): a comparative review". Oxford Journal of Archaeology 34(2): 139-156.

Balsera, V.; Díaz-del-Río, P.; Gilman, A.; Uriarte, A. y Vicent, J. M. 2015b: "Approaching the demography of late prehistoric Iberia through summed calibrated date probability distributions (7000-2000 cal BC)". Quaternary International 386: 208-211.

Bentley, R. A.; Price, T. D. y Stephan, E. 2004: “Determining the 'local' Sr-87/Sr-86 range for archaeological skeletons: a case study from Neolithic Europe". Journal of Archaeological Science 31(4): 365-375.

Botella M. 2003: "Patología tumoral ósea". En A. Isidro y A. Malgosa (eds.): Paleopatología: la enfermedad no escrita. Masson. Barcelona: 249-262.

Botella, M.; Alemán, I. y Jiménez, S.A. 2000: Los huesos humanos: manipulación y alteraciones. Ediciones Bellaterra. Barcelona.

Brothwell, D.R. 1981: Digging up bones: the excavation, treatment, and study of human skeletal remains. Oxford University Press. New York.

Brooks, S. y Suchey J. 1990: "Skeletal age determination based on the os pubis: a comparison of the Acsádi-Nemerkéri and Suchey-Brooks methods". Human Evolution 5(3): 227-238.

Bruzek, J. 2002: "A method for visual determination of sex, using the human hip bone". American Journal Physical Anthropology 117: 157-168.
Bueno, P.; Barroso, R. y Balbín, R. de 2005: "Ritual campaniforme, ritual colectivo: la necrópolis de cuevas artificiales del valle de las Higueras, Huecas, Toledo". Trabajos de Prehistoria 62(2): 67-90.

Campo, M. 2003: "Paleopatología de la columna vertebral". En A. Isidro y A. Malgosa (eds.): Paleopatología: la enfermedad no escrita. Masson. Barcelona: 163-193.

Campillo D. 2001: Introducción a la Paleopatología. Bellaterra. Barcelona.

Campillo, D. y Subirà, M. E. 2004: Antropología Fisica para arqueólogos. Ariel Prehistoria. Barcelona.

Campillo, D.; Bertranpetit, J. y Vives, E. 1990: “Cribra orbitalia y osteoporosis hiperostósicas en paleopatología”. Asclepio 42 (1): 365-391.

Carlson, D.; Armelagos, G. y Van Gerven, D. 1974: "Factors influencing the etiology of Cribra orbitalia in Prehistoric Nubia". Journal of Human Evolution 3: 405-410.

Consuegra, S. y Díaz-del-Río, P. 2013: La tierra apropiada. Madrid, una historia para todos 3, Comunidad de Madrid. Madrid.

Deer, W.A.; Howie, R. A. y Zussman, J. 1992: An introduction to the rock forming minerals. Pearson. Harlow.

Díaz-del-Río, P. 1996. "El enterramiento colectivo de El Rebollosillo (Torrelaguna)". Reunión de Arqueología Madrileña. Madrid: 198-200.

Díaz-del-Río, P.; Waterman, A. J.; Thomas, J. T.; Peate, D. W.; Tykot, R. H.; Martínez-Navarrete, Ma .I. y Vicent, J. M. 2017: "Diet and mobility patterns in the Late Prehistory of Central Iberia (4000-1400 cal BC): the evidence of radiogenic $\left({ }^{87} \mathrm{Sr} /{ }^{86} \mathrm{Sr}\right)$ and stable $\left(\delta^{18} \mathrm{O}, \delta^{13} \mathrm{C}\right)$ isotope ratios". Archaeological and Anthropological Sciences. DOI 10.1007/ s12520-017-0480-y.

Díaz-Zorita, M.; Waterman, A.J. y Knudson K.J. 2009: "Explorando la movilidad y los patrones dietarios durante la Edad del Cobre en el suroeste de la Península Ibérica: estudio preliminar bioarqueológico del Tholos de Palacio II (Almadén de la Planta, Sevilla)". Investigaciones histórico-médicas sobre salud y enfermedad en el pasado. IX Congreso Nacional de Paleopatología. Morella: 671-676.

Domínguez Bella, S. 2012: "Archaeomineralogy of prehistoric artifacts and gemstones". En J. M. Herrero y M. Vendrell-Saz (eds.): Archaeometry and Cultural Heritage: the contribution of Mineralogy. Seminarios de La Sociedad Española de Mineralogía, Sociedad Española de Mineralogía y Museo Geominero del Instituto Geológico y Minero de España. Madrid: 5-28.

Duday, H. 1997: “Antropología biológica 'de campo', tafonomía y arqueología de la muerte. En E. Malvido, G. Pereira y V. Tiesler (eds.): El cuerpo humano y su tratamiento mortuorio. Instituto Nacional de Antropología e Historia. Méjico: 91-126. 
Edo, M.; Blasco, A.; Villalba, M. J.; Gimeno, D.; Fernández Turiel, J. L. y Plana, F. 1998: "La caracterización de la variscita del complejo minero de Can Tintorer, una experiencia aplicada al conocimiento del sistema de bienes de prestigio durante el neolítico". En J. Bernabeu, T. Orozco y X. Terradas (eds.): Los recursos abióticos en la Prehistoria. Caracterización, aprovisionamiento e intercambio. Universitat de València. Valencia: 83-110.

Etxeberria, F. 1993: “Aspectos macroscópicos del hueso sometido al fuego. Revisión de las cremaciones descritas en el País Vasco desde la Arqueología”. Munibe 46: 111-116.

Fernández-Crespo, T. 2015: “Aportación de la Arqueoantropología a la dinámica sepulcral de las tumbas megalíticas de Cameros (La Rioja, España)". Trabajos de Prehistoria 72 (2): 218-237. doi: 10.3989/tp.2015.12152.

Fernández-Crespo, T.; Mujika, J. A. y Ordoño, J. 2017: "Aproximación al patrón alimentario de los inhumados en la cista de la Edad del Bronce de Ondarre (Aralar, Guipúzcoa) a través del análisis de isótopos estables de carbono y nitrógeno sobre colágeno óseo". Trabajos de Prehistoria 73(2): 325-334. doi: 10.3989/tp.2016.12177.

Flores, R. y Garrido, R. 2014: “Campaniforme y conflicto social: evidencias del yacimiento de Humanejos (Parla, Madrid)". Actas de las novenas jornadas de Patrimonio Arqueológico en la Comunidad de Madrid (Madrid 2012): 159-167. Madrid.

Gilman, A. 2001: "Assessing political development in Copper and Bronze Age Southeast Spain”. En J. Haas (ed.): From leaders to rulers. Kluwer Academic/Plenum Publishers. Nueva York: 59-81.

Gonçalves, V. S. 2008: As ocupações Pré-Históricas das Furnas do Poço Velho (Cascais). Colecção Cascais, Tempos Antigos. Câmara Municipal. Cascais.

Grubbs, F. 1969: "Procedures for detecting outlying observations in samples". Technometrics 11(1): $1-21$.

Heras, C. M.; Bastida, A. B. y Galera, V. 2014: "Vida y muerte en el poblado calcolítico de 'El Perdido' (Torres de la Alameda, Madrid). Primeras aportaciones". Actas de las novenas Jornadas de Patrimonio Arqueológico en la Comunidad de Madrid (Madrid 2012): 199-211. Madrid.

Jordá, J. F. y Mestres, J. S. 1999: “El enterramiento calcolítico precampaniforme de Jarama II: una nueva fecha radiocarbónica para la Prehistoria Reciente de Guadalajara y su integración en la cronología de la región". Zephyrus 52: 175-190.

Kohn, M. J. y Cerling, T. E. 2002: "Stable isotope compositions of biological apatite". Reviews in mineralogy and geochemistry 48(1): 455-488.

Kunst, M. y Rojo, M. (eds.) 2002: Sobre el significado del fuego en los rituales funerarios del neolítico. Studia Archaeologica 91, Universidad de Valladolid. Valladolid.
Lai, L. 2008: The interplay of economic, climatic and cultural change investigated through isotopic analyses of bone tissue: the case of Sardinia 4000-1900 B.C. PhD Thesis. University of South Florida.Tampa. http://scholarcommons.usf.edu/etd/353.

Liesau, C. y Blasco, C. 2015: "La diversidad campaniforme en el mundo funerario: algunos ejemplos de la cuenca media/alta del Tajo en el interior peninsular". Arqueología y Prehistoria del Interior Peninsular 3 extra. Homenaje a Rodrigo de Balbín Behrmann: 272-286.

Liesau, C.; Blasco, C.; Ríos, P. y Flores, R. 2015: “La mujer en el registro funerario campaniforme y su reconocimiento social". Trabajos de Prehistoria 72 (1): 105-125.

Liesau, C. y Morales, A. 2012: "Las transformaciones económicas del Neolítico en la Península Ibérica: la ganadería”. En M.Á. Rojo, R. Garrido e I. García-Martínez de Lagrán (eds.): El neolítico en la Península Ibérica y su contexto europeo. Cátedra. Madrid: 107-128.

Liesau, C.; Ríos, P.; Vega, J.; Menduiña, R. y C. Blasco 2014: "Buscando los ancestros: la manipulación de los restos de las tumbas campaniformes en Camino de las Yeseras (San Fernando de Henares, Madrid)". Actas de las novenas jornadas de Patrimonio Arqueológico en la Comunidad de Madrid (Madrid 2012): 137-148. Madrid.

Liversidge H. M.; Herdeg B. y Rösing F. W. 1998: "Dental age estimation of non-adults. A review of methods and principles". En K. W. Alt, F. W. Rösing y M. Teschler-Nicola (eds.): Dental Anthropology. Fundamentals, limits and prospects. Springer. Viena: 419-442.

Nájera, T.; Molina, F.; Jiménez-Brobeil, S.A.; Sánchez Romero, M.; Al Oumaoui, I.; Aranda, G.; DelgadoHuertas, A. y Laffranchi, Z. 2010: "La población infantil de la Motilla del Azuer: Un estudio bioarqueológico". Complutum 21: 69-102.

Odriozola, C. P. 2015: "A new approach to determine the geological provenance of variscite artifacts using the P/Al atomic ratios". Archaeological and Anthropological Sciences 7(3): 329-350. doi:10.1007/ s12520-014-0195-2.

Odriozola, C. P.; Linares, J.A. y Hurtado, V. 2010: "Variscite source and source analysis: testing assumptions at Pico Centeno (Encinasola, Spain)". Journal of Archaeological Science 37: 3146-3157.

Ortner D. 2003: Identifications of pathological conditions in human skeletal remains. Smithsonian Institution Press. Washington.

Pérez Villa, A. 2015: Pautas funerarias y demográficas de la Edad de Bronce en la cuenca media y alta del Tajo. Bibliotheca Praehistorica Hispana 31, Consejo Superior de Investigaciones Científicas. Madrid.

Querré, G.; Herbault, F. y Calligaro, T. 2008: "Transport of Neolithic variscites demonstrated by PIXE analysis". X-Ray Spectrometry 37: 116-120.

Trab. Prehist., 74, N. ${ }^{\circ}$ 1, enero-junio 2017, pp. 68-85, ISSN: 0082-5638

doi: $10.3989 /$ tp.2017.12184 
Roberts, W. L.; Campbell, T. J. y Rapp, G. R. 1990: Encyclopedia of minerals. Van Nostrand Reinhold.

Scheuer, L. y Black, S. 2000: Developmental Juvenile Osteology. Academic Press. Londres.

Silva, A.M.; Leandro, I.; Pereira, D.; Costa, C. y Valera, A.C. 2015: "Collective secondary cremation in a pit grave: a unique funerary context in Portuguese Chalcolithic burial practices". Homo, Journal of Comparative Human Biology 66: 1-14.

Soler, J. A. 2002: Cuevas de inhumación múltiple en la Comunidad Valenciana. Bibliotheca Archaeologica Hispana 17, Real Academia de la Historia y Diputación Provincial de Alicante. Madrid-Alicante.

Soler, J. A.; Roca de Togores, C.; Esquembre, M. A.; Gómez, O.; Boronat, J.; Benito, M.; Ferrer, C. y Bolufer, J. 2016: "Progresos en la investigación del fenómeno de inhumación múltiple en la Marina Alta (Alicante). A propósito de los trabajos desarrollados en la Cova del Randero de Pedreguer y en la Cova del Barranc del Migdia de Xàvia". Del neolític a l'edat del bronce en el Mediterrani occidental. Estudis en homenatge a Bernat Marti Oliver. Trabajos varios del Servicio de Investigación Prehistórica 119, Diputación de Valecia. Valencia: 323-348.

Tankersley, K. B.; Conover, D. G. y Lentz, D. L. 2016: "Stable carbon isotope values $\left(\delta^{13} \mathrm{C}\right)$ of purslane (Portulaca oleracea) and their archaeological significance". Journal of Archaeological Science Reports 7: 189-194.

Tykot, R. H. 2004: "Stable isotopes and diet: you are what you eat". En M. Martini, M. Milazzo y M.
Piacentini (eds.): Physics methods in archaeometry. Proceedings of the international school of physics 'Enrico Fermi' course CLIV. Società Italiana di Fisica. Bolonia: 433-444.

Tykot, R. H.; Falabella, F.; Planella, M. T.; Aspillaga, E.; Sanhueza, L. y Becker, C. 2009: "Stable isotopes and Archaeology in central Chile: methodological insights and interpretative problems for dietary reconstruction". International Journal of Osteoarchaeology 19: 156-170.

Trancho, G.; Botella, M. y Hernández, M. 1991: “Cribra orbitalia: incidencia y distribución en diferentes poblaciones de la Península Ibérica”. Nuevas Perspectivas en Antropología. Diputación Provincial de Granada. Granada: 1011-1028.

Ubelaker D. H. 1978: Human skeletal remains. Taraxacum. Washington.

Vidal, P. 2013: "Cueva Maturras (Ciudad Real, España): el papel del fuego en un contexto funerario del III milenio A.C.". Saguntum 45: 39-47.

Waight T.; Baker J. y Peate, D 2002: "Sr isotope ratio measurements by double-focusing MCICPMS: techniques, observations and pitfalls". International Journal of Mass Spectrometry 221 (3): 229-244.

Waterman, A. J.; Thomas, J. T.; Díaz-del-Río, P.; Consuegra, S.; Pérez-Villa, A. y Peate D. W. 2014: "An investigation of mobility patterns in the late prehistoric communities of central Spain (Madrid) using ${ }^{87} \mathrm{Sr} /{ }^{86} \mathrm{Sr}$ isotope ratios. American Journal of Physical Anthropology 153 (S58): 267. 